EDA) fused to the cytokine interleukin-10. Dekavil is currently in phase II clinical development for the treatment of rheumatoid arthritis (RA).

Objectives: In the phase lb dose escalation study, the primary objective was to explore safety, tolerability and the maximum tolerated dose of Dekavil when administered in combination with methotrexate (MTX). The aim of the currently ongoing phase II study is to assess therapeutic activity of Dekavil plus MTX over MTX alone by measuring the mean change from baseline of DAS28-CRP. Immunogenicity of F8IL10 and its PK and PD profile will also be explored.

Methods: Patients with active RA despite MTX therapy and who failed anti-TNF treatment are the target population of both studies. In the phase $\mathrm{lb}$ trial, cohorts of 3-6 patients were treated with escalating doses of Dekavil $(6,15,30,60,110$, $160,210,300,450$ and $600 \mu \mathrm{g} / \mathrm{kg}$ ) in combination with a fixed dose of MTX (10-15 mg). In the multicenter, double-blind, placebo-controlled phase 2 study, patients are randomized into two treatment groups (Dekavil 30 or $160 \mu \mathrm{g} / \mathrm{kg}$ plus MTX) and one placebo group (placebo plus MTX). Dekavil is administered once weekly by s.c. injection for a maximum of 8 weeks in both studies.

Results: Dekavil has been shown to be well tolerated up to the highest investigated dose $(600 \mu \mathrm{g} / \mathrm{kg})$ and an MTD was not reached. In 33 out of 34 patients treated in the phase 1 study, no DLTs, no SAEs and no SUSARs have been reported. One patient in cohort $9(450 \mu \mathrm{g} / \mathrm{kg})$ experienced a DLT (G2 purpura) and a SAE (G2 dyspnea, not drug related). The patient received corticosteroids and fully recovered within one week. Mild injection site reactions were the most frequently observed adverse events and occurred in $62 \%$ of the patients. Furthermore, two cases of drug related anemia (G2 and G3) were reported in this study. All adverse reactions resolved completely. At the first efficacy assessment after 4 cycles of treatment, $48 \%$ of evaluable patients $(16 / 33)$ revealed ACR and/or EULAR responses. The fraction of responding patients increased to $57.7 \%(15 / 26)$ after 8 cycles of treatment. Two patients benefited from ACR70 responses for more than 12 months after the last drug administration. As of January 2017, 22 out of 87 patients have been treated in the phase 2 clinical study and neither SUSAR nor treatment-related deaths were recorded.

Conclusions: The currently available data suggest that Dekavil is a safe and promising novel therapeutic for the treatments of RA.

Disclosure of Interest: M. Galeazzi: None declared, G. Sebastiani: None declared, R. Voll: None declared, J. Wollenhaupt: None declared, O. Viapiana: None declared, J. Dudler: None declared, E. Selvi: None declared, C. Baldi: None declared, M. Bardelli: None declared, B. Bannert: None declared, S. Finzel: None declared, C. Specker: None declared, P. Sarzi Puttini: None declared, F. Bootz Employee of: Philochem AG, D. Neri Shareholder of: Philogen SpA DOI: 10.1136/annrheumdis-2017-eular.4840

\section{OP0100 OVERALL CANCER RISK IN PATIENTS WITH RHEUMATOID ARTHRITIS TREATED WITH TNF INHIBITORS, TOCILIZUMAB, ABATACEPT, OR RITUXIMAB}

H. Wadström, T. Frisell, J. Askling on behalf of The ARTIS study group. Department of Medicine, Solna, Karolinska Institutet, Stockholm, Sweden

Background: Immune incompetence may lower host surveillance against incipient tumours. Conversely, immune therapies have emerged as a promising therapeutic approach to cancer. Malignancies thus constitute an important aspect of the safety of biologics as used in Rheumatology, including agents targeting TNF, CD20 and IL6, and immunomodulation using CTLA4. Whereas previous reports concerning TNF inhibitors (TNFi) and risk of malignancies in rheumatoid arthritis (RA) have mostly been reassuring, risks with other biological disease modifying anti-rheumatic drugs (bDMARDs) are less studied.

Objectives: To assess the risk of malignancies in patients with RA treated with bDMARDs.

Methods: Through linkages of Swedish national and population-based registers we assembled cohorts of patients with RA initiating (Jan 2006 through Dec 2014) a first ever treatment of tocilizumab, abatacept, rituximab, or a TNFi, one cohort of patients initiating a second TNFi, one cohort of biologics-naïve csDMARD treated RA. Through linkage with the Swedish Cancer Register information on incident cancers was collected. Outcomes were defined as a first ever solid or hematologic malignancy excluding non-melanoma skin cancer (NMSC) during follow-up. Patients with a previous malignancy were excluded. Patients were followed from treatment start until death, emigration, outcome or end of follow up (Dec 2014). Hazard ratios were calculated using Cox-regression adjusted for age, sex, educational level, comorbidities, sero-positivity, number of hospitalizations and days spent in inpatient care, use of prednisolone at baseline, use of nonsteroidal anti-inflammatory drugs (NSAIDs) at baseline, number of prescription drugs at baseline, and sick leave and disability (yes/no) the year before cohort entry.

Results: Adjusted for age, sex, disease- and treatment characteristics (see above), and educational level, there were no statistically significant differences in risk of a first solid or hematologic malignancy between initiators of tocilizumab, abatacept, rituximab, or a first- or second TNFi, and RA patients treated with csDMARDs.

Table 1. Number of persons, events, crude incidence, and hazard ratios for a first invasive solid or hematologic malignancy excluding NMSC

\begin{tabular}{lcccc}
\hline $\begin{array}{c}\text { Outcome definition } \\
\text { Cohort }\end{array}$ & $\begin{array}{c}\text { Number of persons } \\
\text { at risk }\end{array}$ & $\begin{array}{c}\text { Number of } \\
\text { events }\end{array}$ & $\begin{array}{c}\text { Crude incidence } \\
\text { per 10,000 pys }\end{array}$ & $\mathrm{HR}^{*}$ \\
\hline $\begin{array}{l}\text { First invasive solid or hematologic malignancy } \\
\text { excluding NMSC }\end{array}$ & & & \\
Tocilizumab & 1408 & 30 & 80 & $0.78(0.54-1.12)$ \\
Abatacept & 1565 & 45 & 104 & $0.95(0.70-1.28)$ \\
Rituximab & 2793 & 108 & 103 & $0.86(0.70-1.04)$ \\
First TNFi & 9355 & 369 & 93 & $0.91(0.82-1.01)$ \\
Second TNFi & 3610 & 129 & 87 & $0.88(0.73-1.05)$ \\
csDMARD RA & 40071 & 2797 & 131 & 1 (reference) \\
\hline${ }^{*}$ Adjusted for age, sex, disease- and treatment characteristics, and educational level.
\end{tabular}

Conclusions: The overall risk of malignancies among RA patients initiating, tocilizumab, abatacept, rituximab, or a first- or second TNFi in clinical practice did not differ substantially from that of RA patients treated with csDMARDs. Increased risk of tumours at specific sites, or with longer latency, cannot be excluded.

Disclosure of Interest: None declared

DOI: 10.1136/annrheumdis-2017-eular.4048

\section{OP0101 RISK OF OPPORTUNISTIC INFECTIONS IN PATIENTS WITH RHEUMATOID ARTHRITIS INITIATING ABATACEPT: ANALYSIS OF ALL AVAILABLE CLINICAL TRIAL DATA}

T. Simon $^{1}$, T. Gelarden ${ }^{1}$, E. Nkhoma ${ }^{1}$, M. Zhou ${ }^{1}$, S. Banerjee ${ }^{1}$, K. Winthrop ${ }^{2}$ ${ }^{1}$ Bristol-Myers Squibb, Princeton; ${ }^{2}$ Oregon Health \& Science University, Portland, United States

Background: Opportunistic infections (OI) during treatment with abatacept (ABA) have been previously reported but are lacking a comprehensive analysis.

Objectives: To present the overall incidence rates of $\mathrm{Ol}$ and herpes infections observed in patients (pts) receiving ABA using combined clinical trial data.

Methods: Ol adverse events were summarized from 16 clinical trials (both placebo-controlled and cumulative abatacept exposure); all pts randomized to placebo were on a non-biologic DMARD. Incidence rates (per 100 person-years [p-y]) were calculated by the number of pts experiencing the first event divided by the total number of $p-y$ of exposure. The $p-y$ of exposure was censored at the time of the first event, death, discontinuation or end of study. Random effects metaregression was performed across the trials to estimate the frequency of $\mathrm{Ol}$ after adjusting for between-study heterogeneity. Ol were identified using a pre-specified list in the setting of biologic therapy for patients with RA. Criteria for consideration were based on type, location of the infection and causing organism. Excluded from the list were non-specific infections caused by organisms considered to be opportunistic, but common in the general population.

Results: A total of 7044 pts with RA with $\sim 21,330$ p-y of ABA exposure were included in the cumulative randomized trial data (Table). The frequency of OI

Abstract OP0101 - Table 1

\begin{tabular}{|c|c|c|c|c|c|c|}
\hline \multirow[t]{2}{*}{ Infection Outcome } & \multicolumn{2}{|c|}{$\begin{array}{c}\text { Abatacept }(\mathrm{N}=2653) \\
\mathrm{p}-\mathrm{y}=2355\end{array}$} & \multicolumn{2}{|c|}{$\begin{array}{c}\text { Placebo }(N=1485) \\
p-y=1253\end{array}$} & \multicolumn{2}{|c|}{$\begin{array}{c}\text { Cumulative abatacept }(\mathrm{N}=7044) \\
\mathrm{p}-\mathrm{y}=21,330\end{array}$} \\
\hline & $\mathrm{N}(\%)$ & $\mathrm{IR} / 100 \mathrm{p}-\mathrm{y}(95 \% \mathrm{Cl})$ & $\mathrm{N}(\%)$ & $\mathrm{IR} / 100 \mathrm{p}-\mathrm{y}(95 \% \mathrm{Cl})$ & $\mathrm{N}(\%)$ & IR/100 p-y $(95 \%$ Cl) \\
\hline Opportunistic infections* & $4(0.2)$ & $0.17(0.05,0.43)$ & $7(0.5)$ & $0.56(0.22,1.15)$ & $45(0.6)^{\dagger}$ & $0.21(0.15,0.28)^{\dagger}$ \\
\hline Bronchopulmonary aspergillosis & $1(<0.1)$ & $0.04(0,0.2)$ & 0 & 0 & $2(<0.1)$ & $0.01(0.00,0.03)$ \\
\hline Eye infection fungal & $1(<0.1)$ & $0.04(0,0.2)$ & 0 & 0 & $3(<0.1)$ & $0.01(0.00,0.04)$ \\
\hline Gastrointestinal candidiasis & 0 & 0 & $1(<0.1)$ & $0.08(0,0.4)$ & - & - \\
\hline Fungal oesophagitis & 0 & 0 & $1(<0.1)$ & $0.08(0,0.4)$ & $1(<0.1)$ & $0.00(0.00,0.03)$ \\
\hline Meningitis cryptococcal & 0 & 0 & $1(<0.1)$ & $0.08(0,0.4)$ & - & - \\
\hline Oesophageal candidiasis & 0 & 0 & $1(<0.1)$ & $0.08(0,0.4)$ & $7(0.1)$ & $0.03(0.01,0.07)$ \\
\hline Pneumocystis jirovecii pneumonia & 0 & 0 & $1(<0.1)$ & $0.08(0,0.4)$ & $1(<0.1)$ & $0.00(0.00,0.03)$ \\
\hline Pneumonia pseudomonal & $1(<0.1)$ & $0.04(0,0.2)$ & 0 & 0 & $1(<0.1)$ & $0.00(0.00,0.03)$ \\
\hline Respiratory moniliasis & 0 & 0 & $1(<0.1)$ & $0.08(0,0.4)$ & $2(<0.1)$ & $0.01(0.00,0.03)$ \\
\hline Tuberculosis & $1(<0.1)$ & $0.04(0,0.2)$ & $1(0.1)$ & $0.08(0,0.4)$ & $17(0.2)^{\ddagger}$ & $0.08(0.05,0.13)^{\ddagger}$ \\
\hline \multicolumn{7}{|l|}{ Herpes } \\
\hline Herpes simplex & $57(2.1)$ & $2.5(1.9,3.2)$ & $22(1.5)$ & $1.8(1.1,2.7)$ & $60(0.9)$ & $0.28(0.22,0.37)$ \\
\hline Herpes zoster & $44(1.7)$ & $1.9(1.4,2.5)$ & $21(1.4)$ & $1.7(1.1,2.6)$ & $284(4)$ & $1.38(1.22,1.55)$ \\
\hline Herpes virus infection & $5(0.2)$ & $0.2(0.1,0.5)$ & $4(0.3)$ & $0.3(0.1,0.8)$ & - & - \\
\hline
\end{tabular}

${ }^{*}$ Except herpes; ${ }^{\dagger} \mathrm{n}(\%)$ for SAE was 19 and IR/100 p-y was $0.1(95 \% \mathrm{Cl} 0.05,0.14) ;{ }^{\ddagger} \mathrm{n}(\%)$ for SAE was 11 and IR/100 p-y was 0.05 (95\% CI $\left.0.03,0.09\right) ;{ }^{-}-$indicates value is not available. SAE = serious $\mathrm{AE}$ 